\title{
Research on the Application of Group Guidance in Teaching Mental Health for Secondary Vocational Students
}

\author{
Yuanming Li \\ Anhui Fuyang Industrial Economics School (Economics School Campus), Sha He Road No. 34, Ying Zhou \\ District, 236018, Fuyang, Anhui
}

Keywords: vocational education; mental health; group guidance

\begin{abstract}
The development of vocational education has received much attention in recent years. While promoting the development of vocational education, the comprehensive growth and development of students in vocational schools is an unavoidable problem. At present, many vocational schools are carrying out mental health education, but from the current situation of mental health education, the efficiency of mental health education is relatively low, and students' lack of positive participation in mental health education and teaching is undisputed. Group counseling is a good combination of physical and mental health education in secondary vocational schools. This paper will also discuss how to apply group counseling in secondary vocational mental health education [1].
\end{abstract}

\section{Introduction}

mental health education is an important component in the contemporary education system. In the development of secondary vocational education, it also needs to foster a higher status of mental health education and play a more fundamental role in mental health education. However, in many secondary vocational schools, the development of mental health education is not good enough. Many factors also have a negative impact on the effective development of mental health education and teaching activities. Despite the excellent group counseling and mental health education method can better applied in secondary vocational school mental health education in the teaching of secondary vocational school teachers mental health, but for how the application of the lack of a complete cognition, explore the application strategy of group counseling in mental health education in secondary vocational schools in the teaching strategy is also very necessary.

\section{Group guidance and psychological health education for secondary vocational students}

Most students are at a crucial stage of three formation, under the concept of modern education, the school should bear the responsibility of basic knowledge education not only, more to cultivate what kind of people, how to cultivate people of more thinking. Secondary vocational mental health education is not simply a mental health education in secondary vocational schools. It is a simple task to deepen mental health education in secondary vocational schools. We must bear more educational responsibilities. From the basic role of mental health education in secondary vocational school, it is better to help secondary vocational students to better understand themselves and better understand the society. There are bad learning mood or other types of mental health problems in the teaching of secondary vocational school students, vocational school mental health education carried out and also can be used to solve the psychological health problems of the series, this is for the protection of students' physical and psychological health and overall balanced development also has positive significance [2].

Group counseling in mental health education in secondary vocational teaching although it is only a specific teaching methods and strategies, but its practical value and role should not be underestimated, especially in the current vocational mental health education teaching has obvious effect of the homogenization of the problem, group counseling can often become the starting point of mental health education in secondary vocational teaching innovation. Once group counseling can 
become a general choice of mental health education in secondary vocational schools, the innovative color of secondary vocational mental health education and teaching can be more obvious, and ordinary students can also participate in mental health education better. After accumulating more group teaching experience, teachers can better carry out mental health education practice under the perspective of innovative teaching. Mental health problems of individual students can also be better solved under group guidance teaching method.

\section{Problems in teaching of mental health education in secondary vocational school}

Secondary vocational mental health education teaching, many teachers choose and apply methods are outdated, secondary vocational mental health education mode is more serious mechanical color. As the teaching mode of mental health education is relatively rigid, the selection and application of the methods are relatively old, and the actual efficiency of mental health education in secondary vocational education is relatively low. In addition, many secondary vocational schools pay less attention to mental health education and teaching. Compared with general subject teaching, the advantage of mental health education teaching is not obvious. The classroom teaching is still the main form of many secondary vocational school mental health education, which can meet the teaching needs of mental health education in a certain extent, but in the long run, classroom teaching is the main teaching form, teaching the development of mental health education in secondary vocational schools will be directly affected, classroom teaching for the teaching of mental health education for secondary vocational school innovation enhances the time and space constraints, which is not conducive to effective teaching activities in vocational mental health education.

Although a lot of secondary vocational schools carry out mental health education in normalization, it is easy to find that a lot of secondary vocational school students have low sense of identity and participation in mental health education and teaching from the perspective of teaching participation. In adolescence and rebellious period, secondary vocational school students have some conflicting feelings for mental health education and teaching. When secondary vocational mental health education and teaching methods are outdated, some students also lose their enthusiasm to accept mental health education. Besides, there are some deviations in the teaching orientation of mental health education in secondary vocational schools, which not only affects the state of related teachers in education and teaching activities, but also makes many students unable to participate in mental health education effectively. Once the secondary vocational mental health education teaching, teachers' "teaching" and students' "learning" can not produce a good connection, education will be in a state of mutual separation, which is actually not conducive to the development of secondary vocational mental health education teaching [3].

The key is the lack of specific problems of mental health education in secondary vocational teaching, and unable to be established under the focus of teaching better, there will be a lack of overall teaching level, teaching effect is similar to that of "flat narrative", the mental health of students more can not be effectively guaranteed. Even if the mental health teachers in secondary vocational schools carry out mental health education according to the syllabus and plan, students' awareness of mental health education and mental health education will gradually fade down under the lack of mental health education. Mental health education should be a kind of special education with rich contents and various forms. Its ability to occupy a place in all levels of education is directly related to its important functions. Secondary vocational schools can not clearly identify the key points of teaching, which illustrates the embarrassing position of mental health education in secondary vocational education appropriately, and even has a negative impact on the effectiveness of secondary vocational education teaching.

The lack of teaching characteristics in secondary vocational mental health education is also significant. The lack of teaching characteristics of mental health education and teaching also leads to the attractiveness of the whole teaching. From the teaching form, a lot of secondary school mental health education teachers to set the completion of the teaching plans and teaching objectives more attention, while the traditional teaching method can achieve the desired teaching goal as in the 
past, their enthusiasm for education and teaching innovation promotion will be affected. After analyzing the teaching of mental health education in some secondary vocational schools, we can see that many secondary vocational schools have obvious homogenization in mental health education and teaching activities, which indicates that the overall innovation degree of mental health education in secondary vocational schools is very low. Under the background of great concern for innovation in the development of education, teachers' mechanically mental health education is totally dependent on books for mental health education, and is not conducive to the improvement of mental health level of secondary vocational school students.

\section{The application strategy of group counseling in teaching mental health in secondary vocational school}

Secondary vocational mental health education has greater innovation pressure. Secondary vocational school mental health education teachers can help with the introduction and application of group counseling, and make specific innovations for the form of mental health education. Although group guidance has appeared in the 90s of last century, it has been widely used in the teaching of mental health education at the stage of school education in developed countries. But its application has not been fully applied in China. Especially in secondary vocational education stage, group counseling has a higher degree of novelty in mental health education and teaching. Secondary vocational school teachers can also make innovations in teaching form with the introduction and application of group counseling. Group counseling can become an innovative choice of mental health teaching and teaching in secondary vocational schools. Secondary vocational school teachers should gradually increase their awareness of group counseling, and actively apply group teaching guidance in specific teaching. Through the continuous accumulation of group guidance and teaching experience, secondary vocational teachers can also be more adept and easy to carry out innovative teaching attempts in the follow-up teaching [4].

Good application of group counseling teachers will set the group as the first work in the mental health education, has a certain similarity with the body of students under the concept of cooperative learning, teachers can set up science only in the "group", group counseling for secondary vocational school mental health education in order to better play the positive effects out. Generally speaking, mental health education teachers in secondary vocational schools can set up groups according to their gender and personality characteristics, and control group size according to the contents of established mental health education. But in the actual teaching, the students in the same class will show a strong difference in their mental health and character characteristics. It also requires that the teachers of mental health education should enhance their understanding of the mental health of the students and carry out the application of group guidance. Group counseling cannot be a vocational mental health education only, there were obvious psychological disorders and mental health problems in some students, teachers also want to carry on the guidance of a mental health, avoid the personalized features have a negative impact on the development of group counseling teaching activities [5].

Psychological health education in secondary vocational schools needs to set specific teaching goals and pay attention to the efficient achievement of the overall teaching goal. Once the group counseling is applied in secondary vocational mental health education, it needs more group guidance to set up teaching objectives, and achieves teaching objectives under the influence of relatively new teaching methods. For example, secondary vocational teachers can cultivate students' social ability and develop cooperative spirit as the teaching goal of stage mental health education. In practical teaching, teachers can set foot such as multiperson mental health education practice activities, the limitations of time and space so that the mental health education from classroom teaching. Under the application of group counseling, teachers should better identify students' participation and create new educational goals according to the needs of students' mental health education, so as to continuously enhance the direction and goal of mental health education in secondary vocational schools.

The application of group guidance in the teaching of mental health education in secondary 
vocational school can not be used in the form of form, and can not be applied to it according to the established teaching thinking and mode. It is suggested that all secondary vocational schools and mental health education teachers should pay attention to the increase of diversified colors of mental health education under group guidance teaching method, and try to enhance the practical primary school value of group counseling through thematic teaching. Secondary vocational schools can carry out and carry forward the traditional culture perspective, to carry out the theme of psychological health education related to traditional culture. Such as "abandoned" traditional culture theme educational activities or debate activities within the group, can not only enhance the students understanding of the traditional culture, and actively guide the teachers can also make excellent traditional culture content better influence students' mental health. Secondary vocational school teachers can combine different themes to carry out group counseling psychological health education for secondary vocational school students, and group counseling itself can show itself better in mental health education and teaching [6].

\section{Conclusions}

Group counseling has obvious application value in mental health education in secondary vocational schools, but this value and educational function play a direct role in mental health teachers in secondary vocational schools. Secondary vocational mental health teachers have strong control over mental health education and teaching activities. They also need to deepen their understanding of group counseling. This is an attempt to apply group counseling in specific teaching. It is worth noting that the teaching situation of mental health education has obvious differences, the mental health of teachers in different schools to help this teaching method in the application of group, good for the mental health education of teaching practice, to avoid improper application of mental health education has a negative impact.

\section{References}

[1] Cryan. A manual for use of parents and students of Corvallis High School. [J]. Scottish Geographical Magazine, 1976, 92(1):61-63.

[2] Mahler K, Niedzielskieichner N. The role of expanded learning opportunities in New York State school reform [J]. 2012.

[3] Yamamoto S. Science and Technology in Higher Education [J]. Journal of Science Policy \& Research Management, 2010, 24:298-299.

[4] Ngai, Suet-man, Beatrice, et al. Evaluation of a rational emotional behaviour therapy (REBT) group programme for students with low self-esteem [J]. Hku Theses Online, 1998.

[5] Zellers D F, Howard V M, Barcic M A. Faculty Mentoring Programs: Reenvisioning Rather than Reinventing the Wheel [J]. Review of Educational Research, 2008, 78(3):552-588.

[6] Fleser T, Szuhanek R, Binchiciu E, et al. Attitudes and Risks Concerning the Management of the Career of Young Engineers[J]. Advanced Engineering Forum, 2015, 13:295-302. 